\title{
Research on Energy-Saving by Green Technology in a Shenyang University
}

\author{
Xin $\mathrm{Li}^{1,2, \mathrm{a}}$, Yemin Zhang ${ }^{3, \mathrm{~b}}$, Rui Bai ${ }^{1, \mathrm{c}}$ \\ ${ }^{1}$ Shenyang University, Institute of architectural engineering, Shenyang, China \\ ${ }^{2}$ China State Key Laboratory of Building Safety and Built Environment, Beijing, China \\ ${ }^{3}$ Shenyang University, Shenyang, China \\ a55047430@qq.com, bm1964@163.com, '815770349@qq.com
}

Keywords: consumption; energy-saving; green technology

Abstract. According to the statistics, the energy consumption of the university is more than the social average consumption. Coupled with the construction of energy-saving requirements, the external walls and roof are not adopted, the structure of the performance is poor.At the same time, relevant standards is generally less than and building energy consumption, indoor thermal environment is not ideal and so on.It is included three aspects that recycling of resources, building energy-saving technologies, energy consumption monitoring platform for building.

\section{Project profile}

Shenyang University is responsible for education, scientific research and social services. It is an important community in the community, but also is the resources, energy consumption of large, involving a wide range, the number of large, diverse forms. According to the statistics, the energy consumption of the university is more than the social average consumption. For example, the average power consumption is about 5 times to the per capita. Because most of the campus construction has been built up to more than ten years, after many years of use and lack of maintenance, the existing to the wall surface aging phenomenon, coupled with the construction of energy-saving requirements, the external walls and roof are not adopted, the structure of the performance is poor.At the same time, relevant standards is generally less than and building energy consumption, indoor thermal environment is not ideal and so on.

\section{Existing problems in Shenyang university}

More than $80 \%$ of school buildings has been running nearly 15 20 years in Shenyang university. After years of use and lack of maintenance, the surface of wall is aging. At the same time, the construction of building is not considered energy requirements, wall and roof are not adopted insulation measures. So, there is a building energy consumption, indoor thermal environment is not ideal and other issues.

2.1 Building envelope thermal performance

Because of poor performance of building envelope, the construction unit area energy consumption is more than $28 \mathrm{Kg}$ standard coal / square meter, which can not reach the relevant requirements of "public building energy efficiency design standard" (GB50189-2005)[1].

2.2 Indoor thermal environment

Through site investigation, the classroom of south is hot in summer (attic particularly serious), the classroom of northern is cold in winter (on the first floor of the classroom feeling obvious). To improve the level of indoor thermal environment, natural ventilation technology, sun shading technology and other measures should be taken into consideration. Create a good learning environment.

2.3 Building electricity consumption

After field investigation, the phenomenon of waste of electricity in Shenyang university is more serious. General lighting lamp is widely used in classroom and corridor. Phenomenon of classrooms daytime lights, students left forget to turn off the lights, fewer people turn on the lights in a large area 
is existing.At the same time, the multimedia equipment is frequently forgot to turn off the computer after class.

2.4 Building water consumption

Water statistics and constitute analysis showed that the main problems with water as follows: the average water consumption is very higher to everyone student and waste water is serious. It is only $4.2 \%$ of water usage.At the same time,water resources utilization potential is still large[2].

\section{Green energy saving technology}

At present, there is no design standard of the green energy saving reform of public buildings.So,green energy saving technology is selected with reference to the current national standard of "public building energy efficiency design standards" (GB 50189) and combined with the characteristics of the climate and buildings in Shenyang.After calculation and comparison, analysis and research,It is determined that the content of the green energy saving technology in Shenyang University. It is included three aspects that recycling of resources, building energy-saving technologies, energy consumption monitoring platform for building[3].

3.1 Resource recycling

\subsubsection{Campus rainwater collection and reuse}

It is configured rainwater diversion facilities on the building roof. Diversion of rainwater is run into the abandoned system underground and then into the municipal pipe network. Because of the water pollution and the content of the roof is small, the water can be reused after simple filtration and natural sedimentation. Reuse of rainwater can be used for campus greening and cleaning work. The rainwater recycling was as shown in Fig. 1.

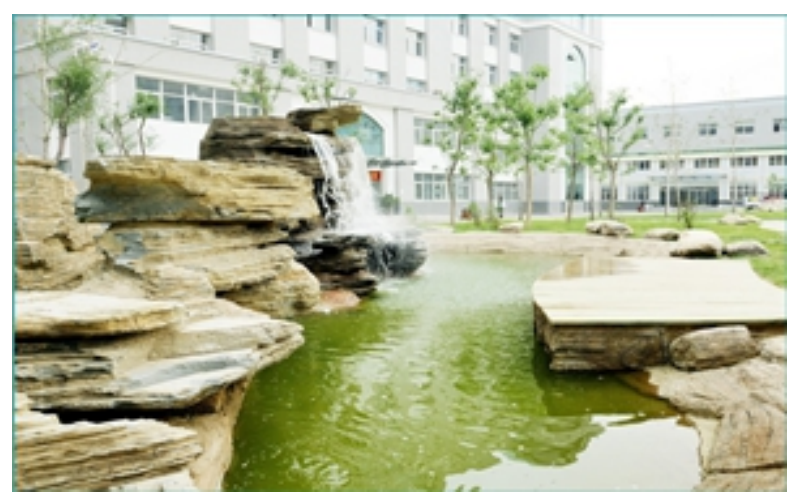

Fig.1 Rainwater recycling

\subsubsection{Sewage ecological treatment technology}

On the basis of the existing sewage treatment technology, the sewage treatment system and energy monitoring platform is networking for further energy saving. Due to historical reasons of campus planning, the building of Shenyang university is adjacent to Dadong Road, some sewage was directly discharged into the municipal pipe network.The greening technology is to channel sewage into the pipe network of campus ecological sewage treatment. At the same time, expanding the processing capacity of campus sewage from $300 \mathrm{~m}^{3} / \mathrm{d}$ to $350 \mathrm{~m}^{3} / \mathrm{d}$. campus sewage after secondary treatment will be used for water supplement of campus greening and the artificial lake.The sewage treatment system and sewage reuse was as shown in Fig. 2 and Fig.3. 


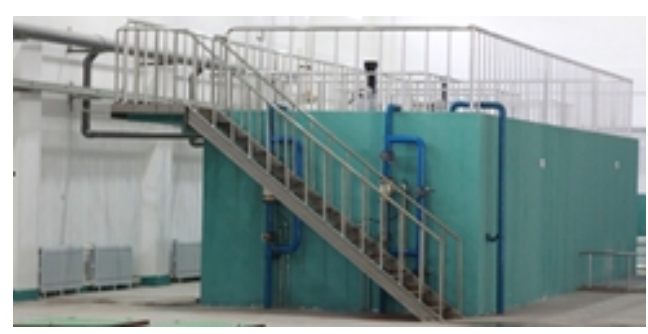

Fig.2 Sewage treatment system

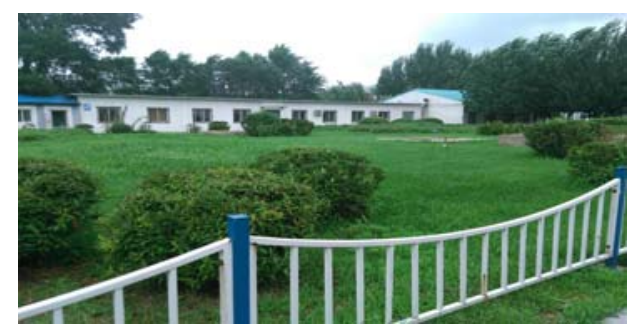

Fig.3 Sewage reuse

\subsubsection{Optimized water source heat pump}

According to the characteristics of cooling load and hot load in Shenyang university,the design load and the spatial distribution of the network of the water source heat pump system will be optimized. Due to the characteristics of school work and rest time, the coldest days(about 5 weeks) in winter and the hottest days in summer(about 6 weeks) are during the school holidays[4]. So, the actual cooling load is corrected by $50 \%$ of the design value. Under the condition of both the campus area and the heat storage capacity, the optimal operation of the water source heat pump heating system is optimized.The Pipe network layout of water source heat pump was as shown in Fig. 4.

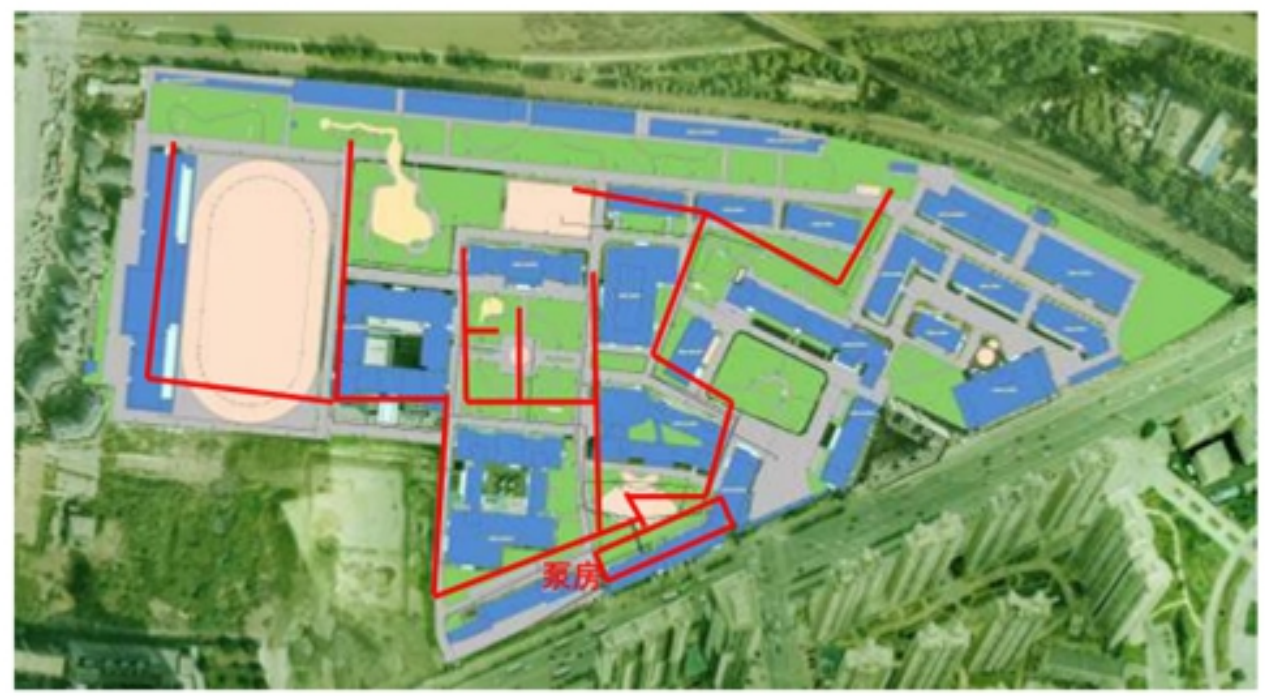

Fig.4 Pipe network layout of water source heat pump

\subsection{Reform existing buildings to green energy waving}

The north building is usually used in the construction of the external wall insulation system due to the structural characteristics. According to the experimental results that section has been transformed building envelope, it can effectively reduce heating energy consumption by more than $20 \%$ through structural transformation.

\subsection{Building energy consumption monitoring platform}

Energy monitoring platform has been built in Shenyang University, it can be centralized monitoring and control of all building energy equipment.It can partial measure for different types, different functions of energy consumption, water consumption.Data is collected, storage and analysis combined with remote data transmission and other technical means.It is the basic statistical data of energy consumption statistics, energy audit, energy efficiency publicity. At the same time, it is the basis for the building energy saving measures of Shenyang University.

\section{Summary}

The existing problems is that the old building, the wall aging, energy consumption and not ideal of indoor thermal environment in Shenyang university by actual investigation. The green energy saving 
scheme is put forward from three aspects: resource recycling, building energy saving technology and energy consumption monitoring platform,which is very effective.

\section{Acknowledgements}

This work was financially supported by the Science and Technology Support Program of National(2013BAJ15B06-01), Opening Funds of State Key Laboratory of Building Safety and Built Environment,Science and Technology Project of Shenyang (F15-114-9-00 ),College Students Innovation and Entrepreneurship Training Program of Shenyang University(201511035131).

\section{References}

[1] Ying Tan. Research on Energy Consumption and Energy Using Characteristics of Typical Public Buildings in Chongqing, Chongqing: Chongqing University,2009.(In Chinese)

[2] Chuanzhi Liang.Research on Building Energy Characteristic of Office Building in Hot Summer and Warm Winter Zone. Tianjin:Tianjin University,2011.(In Chinese)

[3] Zhong Liu. Study on Energy Survey and Energy-saving Measures of Governmental Office Buildings and Large Public Buildings in Chengdu.Chengdu: Xihua University,2014.(In Chinese)

[4] Huiqiang Tang, Jun Ren, Bing Guo. Investigation on office building energy consumption and analysis of energy saving potential in Guangzhou[J]. Energy saving,2008,04:30-32+2.(In Chinese) 